\title{
USO DE DOIS ESPAÇAMENTOS ENTRE GOTEJADORES NA MESMA LINHA LATERAL E SEUS EFEITOS SOBRE A FORMAÇÃO DO BULBO MOLHADO NO SOLO E PARÂMETROS FÍSICOS DE RABANETE.
}

\author{
LEONARDO PRETTO DE AZEVEDO ${ }^{1}$ e JOÃO CARLOS CURY SAAD ${ }^{2}$ \\ ${ }^{1}$ Instituto Federal de Educação, Ciência e Tecnologia de São Paulo, Campus São Roque. Rod. Prefeito Quintino de \\ Lima 2100, São Roque, SP, pretto@,ifsp.edu.br \\ ${ }^{2}$ Departamento de Engenharia Rural, Faculdade de Ciências Agronômicas, Universidade Estadual Paulista, Botucatu, \\ SP, joaosaad@fca.unesp.br
}

\section{RESUMO}

A adoção de sistemas de irrigação de baixo consumo de água e energia na agricultura é importante para o suprimento da crescente demanda global por alimentos. Nesse sentido, torna-se importante o desenvolvimento de técnicas que elevem a uniformidade de aplicação de água em sistemas de irrigação por gotejamento. $\mathrm{O}$ objetivo do trabalho foi comparar a disposição de linhas laterais em irrigação por gotejamento, mediante a formação dos bulbos molhados no solo e parâmetros físicos de rabanete compostas por espaçamento simples entre gotejadores em relação a laterais compostas por dois segmentos, sendo que cada um composto por diferentes espaçamentos entre emissores. Foram feitas duas distribuições de avaliação, conforme o seguinte: 1) linhas laterais convencionais com espaçamento entre emissores de $20 \mathrm{~cm}$ foram comparadas às linhas laterais propostas com espaçamento entre emissores de $24 \mathrm{~cm}$ no segmento inicial e de 20 $\mathrm{cm}$ no segmento final; 2) linhas laterais convencionais com espaçamento entre emissores de 30 $\mathrm{cm}$ foram comparadas às linhas laterais propostas, com espaçamento entre emissores de $36 \mathrm{~cm}$ no segmento inicial e de $30 \mathrm{~cm}$ no segmento final. $\mathrm{O}$ experimento foi conduzido em ambiente protegido na Fazenda Experimental São Manuel, localizada no município de São Manuel-SP, e pertencente à Faculdade de Ciências Agronômicas, UNESP, Botucatu-SP. Utilizou-se um delineamento inteiramente casualizado, em seis tratamentos e quatro repetições. Pelos resultados obtidos percebeu-se que não houve diferença significativa entre os tratamentos para a maioria dos parâmetros avaliados, concluindo-se que diferentes espaçamentos entre gotejadores na mesma linha lateral podem ser utilizados para aumentar seu comprimento.

PALAVRAS-CHAVE: gotejamento, espaçamento entre emissores.

AZEVEDO, L. P; SAAD, J. C. C.

THE USE OF TWO DRIPPERS SPACING IN THE SAME LATERAL LINE, THEIR EFFECTS ON THE SOIL WET BULB AND RADISH PHYSICAL PARAMETERS 


\section{ABSTRACT}

The use of irrigation systems with consumes less water and energy in agriculture is important to supply the growing global demand for food. It is important to develop techniques that will increase the uniformity of water application on drip irrigation systems. The aim of this study was to compare the lateral lines layout in drip irrigation, through the wet bulbs formation in soil and radish physical parameters, composed of single spacing between drippers in relation to lateral lines composed of two emitters spacing in different segments. Two evaluation were carried out: 1) conventional drip lateral lines with $20 \mathrm{~cm}$ emitter spacing were compared to proposed drip lines with $24 \mathrm{~cm}$ emitter spacing in the initial section and $20 \mathrm{~cm}$ emitter spacing in the final section; 2) conventional drip lateral lines with $30 \mathrm{~cm}$ emitter spacing were compared to proposed drip lines with $36 \mathrm{~cm}$ emitter spacing in the initial section and $30 \mathrm{~cm}$ emitter spacing in the final section. The experiment was carried out in a greenhouse of the Sao Manuel Experimental Farm, located at Sao Manuel, SP. The experimental design was entirely randomized, with six treatments and four replications. Results showed no difference among treatments for the most evaluated variables. Thus it is possible to conclude that the use of different spacing between emitters in the same lateral line can be used to increase the line length.

KEYWORDS: drip irrigation, emitter spacing.

\section{INTRODUÇÃO}

O aumento na demanda por alimentos, resultado da expansão demográfica acelerada, vem acompanhado do aumento na demanda por água na agricultura. Dessa forma torna-se imprescindível a adoção de técnicas de uso racional de água na agricultura, promovendo a adoção de sistemas de irrigação de baixo consumo de água e energia, como os sistemas de irrigação por gotejamento. Nesse sentido, é importante o desenvolvimento de novas técnicas de utilização de gotejadores convencionais para elevar a uniformidade de aplicação de água no solo a baixo custo, sem que haja perda de produtividade e qualidade das culturas.

\subsection{Sistema de irrigação por gotejamento}

O sistema de irrigação por gotejamento caracteriza-se pela presença de emissores (gotejadores) pelos quais a água escoa após ocorrer dissipação de pressão ao longo de uma rede de condutos. As vazões de cada emissor geralmente variam de 2 a $20 \mathrm{~L} \mathrm{~h}^{-1}$ e dentre suas vantagens estão a grande economia de água e energia e a excelente uniformidade de aplicação de água, comparado a outros tipos de irrigação (MANTOVANI et al., 2007).

A uniformidade de aplicação de água em áreas irrigadas influencia diretamente o manejo, a eficiência e o custo da irrigação, assim como afeta a qualidade e produtividade da cultura. Santos et al. (2003) afirmam que uma baixa uniformidade de distribuição de água faz com que determinadas plantas fertirrigadas pelo sistema recebam mais água e adubo do que outras, resultando em um desenvolvimento desuniforme dentro do cultivo de uma determinada cultura. 


\subsection{Perda de carga em linhas laterais na irrigação por gotejamento}

Bernardo et al. (2006) definem a perda de carga ao longo da tubulação como a perda atribuída ao movimento da água, de maneira uniforme, ao longo de qualquer trecho de uma canalização de diâmetro constante, constituindo-se no principal tipo de perda na maioria dos projetos de condução de água. Em irrigação por gotejamento, a perda de carga em uma linha lateral corresponde ainda à soma da perda de carga localizada na inserção dos gotejadores à parede do tubo, considerando como uma lateral de múltiplas saídas (gotejadores).

Para emissores convencionais, a vazão dos emissores ao longo da mangueira não é uniforme. Isto porque a distribuição de pressão ao longo desta lateral será decrescente da entrada para o fim, devido às perdas de carga ao longo da tubulação e perdas localizadas. Desta forma, a distribuição de água no solo não ocorreria de maneira uniforme até mesmo entre gotejadores da mesma linha lateral, podendo ocasionar a aplicação de diferentes lâminas de água. Segundo Frizzone et al. (1998), a relação vazão-pressão, a perda de carga ao longo da linha lateral e no emissor e o percurso da água no mesmo, constituem nas características hidráulicas que influenciam diretamente o desempenho do sistema de irrigação por gotejamento. $\mathrm{O}$ dimensionamento da linha lateral é função da variação de pressão ou de vazão permitida. A variação entre o ponto de maior e de menor vazão não deve ultrapassar $10 \%$, o que equivale a uma variação de pressão de 20\%. (KARMELI \& KELLER, 1975; BERNARDO et al., 2006).

Uma alternativa para diminuir os efeitos da perda de carga na linha lateral é a utilização de gotejadores autocompensantes, que permitem dimensionar sistemas com linhas laterais mais longas; porém o custo de aquisição é superior aos gotejadores convencionais, fazendo com que muitos agricultores optem pela diminuição dos custos em detrimento dos benefícios operacionais que esses gotejadores apresentam.

\subsection{Espaçamento entre emissores e a sobreposição de bulbos úmidos}

A água liberada no solo pelos gotejadores propaga-se de maneira tridimensional para as camadas mais profundas, formando o que comumente é conhecido como bulbo molhado ou bulbo úmido. Em irrigação por gotejamento de cultivos adensados ocorre a sobreposição dos bulbos úmido, formando muitas vezes uma faixa úmida de irrigação. Torna-se importante conhecer o diâmetro dos bulbos e a maior distância possível entre emissores da linha lateral, mantendo-se ainda a sobreposição necessária para que se atendam as necessidades hídricas da cultura. Segundo Keller \& Bliesner (1990), o volume de solo úmido é função direta da quantidade total de água aplicada. A aplicação em excesso aumenta a profundidade de penetração de água para abaixo da zona de raízes. Aplicações diárias tendem a minimizar perdas por percolação, mas produzem pequena área molhada. $O$ diâmetro molhado é maior na faixa de 0,15 a $0,30 \mathrm{~m}$ de profundidade, a não ser que altas taxas de aplicação sejam usadas. Segundo os autores, o espaçamento entre emissores deve ser igual ou menor que $80 \%$ do máximo diâmetro molhado, para que se forme uma faixa contínua e uniformemente úmida, concluindo que equações e tabelas somente devem ser utilizadas como estimativas para início de testes de campo. Benami \& Ofen (1984), considerando as relações não-lineares entre as variáveis envolvidas, concluíram que os melhores resultados sempre são conseguidos com testes a campo. 


\subsection{A cultura de rabanete}

O rabanete é uma planta de porte reduzido, da família das Brassicáceas. Ao longo do ciclo, o teor de água útil no solo deve ser mantido próximo a $100 \%$ da capacidade de campo, evitando flutuações para que não ocorram rachaduras. O ciclo do rabanete é um dos mais rápidos entre as hortaliças, com início das colheitas aos 20-30 dias, dependendo da estação do ano (FILGUEIRA, 2000). Segundo Azevedo (2008), são raros os trabalhos sobre manejo da irrigação em rabanete; no entanto, o rabanete é extremamente sensível às flutuações de umidade no solo, sofrendo distúrbios fisiológicos na menor falta ou excesso de água, afetando inclusive a produtividade e diâmetro de raiz, que o torna uma alternativa para estudos de aplicação de água ao solo e seus efeitos sobre a cultura. Pereira et al. (1999), pesquisando diferentes níveis de reposição de água na cultura de rabanete, encontraram valores médios de peso de matéria fresca de 16,07 g a 12,27 g, significativamente diferentes, respectivamente para níveis de reposição de $100 \%$ e $60 \%$ da capacidade de campo. Torres et al. (2003) avaliaram os efeitos da densidade de plantio sobre o peso e diâmetro de raízes de rabanete. Não se observou diferenças estatísticas entre os tratamentos, sendo que o peso de matéria fresca médio variou de $22,04 \mathrm{~g}$ a $28,63 \mathrm{~g}$ e o diâmetro médio variou de $31,49 \mathrm{~mm}$ a $33,57 \mathrm{~mm}$.

O presente trabalho teve como objetivo comparar linhas laterais de dois segmentos diferentes com linhas laterais convencionais, de segmento único, através da análise de parâmetros físicos da cultura de rabanete e da formação dos bulbos molhados no solo.

\section{MATERIAL E MÉTODOS}

\section{1 Área experimental}

O experimento foi conduzido nos meses de janeiro a março de 2008, em ambiente protegido, na Fazenda Experimental São Manuel, localizada no município de São Manuel-SP e pertencente à Faculdade de Ciências Agronômicas, UNESP, Botucatu-SP.

Cada linha lateral proposta foi denominada de Situação e foi composta por dois segmentos distintos, segmento inicial e segmento final, cada segmento formado por uma combinação de pressão e espaçamento entre emissores. A Situação 1 representou uma linha lateral com espaçamento entre emissores de $24 \mathrm{~cm}$ no segmento inicial (calculado segundo metodologia detalhada no item 4.3) e de $20 \mathrm{~cm}$ no segmento final (espaçamento comercial). Essa situação foi comparada à Situação 3 (situação controle), em que a linha lateral apresentou apenas um espaçamento de $20 \mathrm{~cm}$ para todas as seções, inicial e final. Dessa maneira, pôde-se avaliar diferenças entre as seções inicial e final entre linhas laterais de espaçamento único $(20 \mathrm{~cm})$ com linhas laterais de espaçamento variado $(24$ e $20 \mathrm{~cm})$. O mesmo raciocínio foi considerado para as Situação 2 e Situação 4. A Situação 2 representou uma linha lateral com espaçamento entre emissores de $36 \mathrm{~cm}$ no segmento inicial (espaçamento calculado) e de $30 \mathrm{~cm}$ no segmento final (espaçamento comercial). Essa situação foi comparada à Situação 4 (situação controle), em que a linha lateral apresentou apenas um espaçamento $(30 \mathrm{~cm})$. Em todas as Situações adotou-se pressão de $100 \mathrm{kPa}$ no segmento inicial e $70 \mathrm{kPa}$ no segmento final. 


\subsection{Sistema de irrigação}

A água utilizada foi captada de um reservatório central de 40.000 litros, filtrada em filtro de areia e redirecionada para a casa de vegetação por conjunto moto-bomba, em tubulação enterrada de 1" de diâmetro. No interior da estufa, a tubulação foi subdividida em duas linhas principais de irrigação de $3 / 4$ ", uma linha para cada pressão de serviço a ser utilizada (70 e 100 $\mathrm{kPa}$ ). Em cada linha instalou-se uma válvula reguladora de pressão e um manômetro, para verificação da eficiência da válvula durante as irrigações. Em cada parcela instalou-se uma redução da tubulação para $1 / 2$ " de diâmetro, um registro para controle de entrada de água e duas linhas laterais de gotejamento, do tipo drip-tape, espaçadas a $40 \mathrm{~cm}$. A caracterização do sistema de irrigação pode ser melhor compreendida através da Figura 1.

O manejo da irrigação foi realizado pelo método de tensiometria, para elevar o potencial de água no solo de $-25 \mathrm{kPa}$ para $-10 \mathrm{kPa}$, valores adotados respectivamente como tensão de irrigação e capacidade de campo para cultivo de rabanetes em solos arenosos, segundo Sanders (1997). A curva de retenção de água no solo foi obtida no Laboratório de Relações Água-Solo do Departamento de Engenharia Rural da FCA/UNESP - Botucatu, segundo metodologia proposta por Richards (1965). 


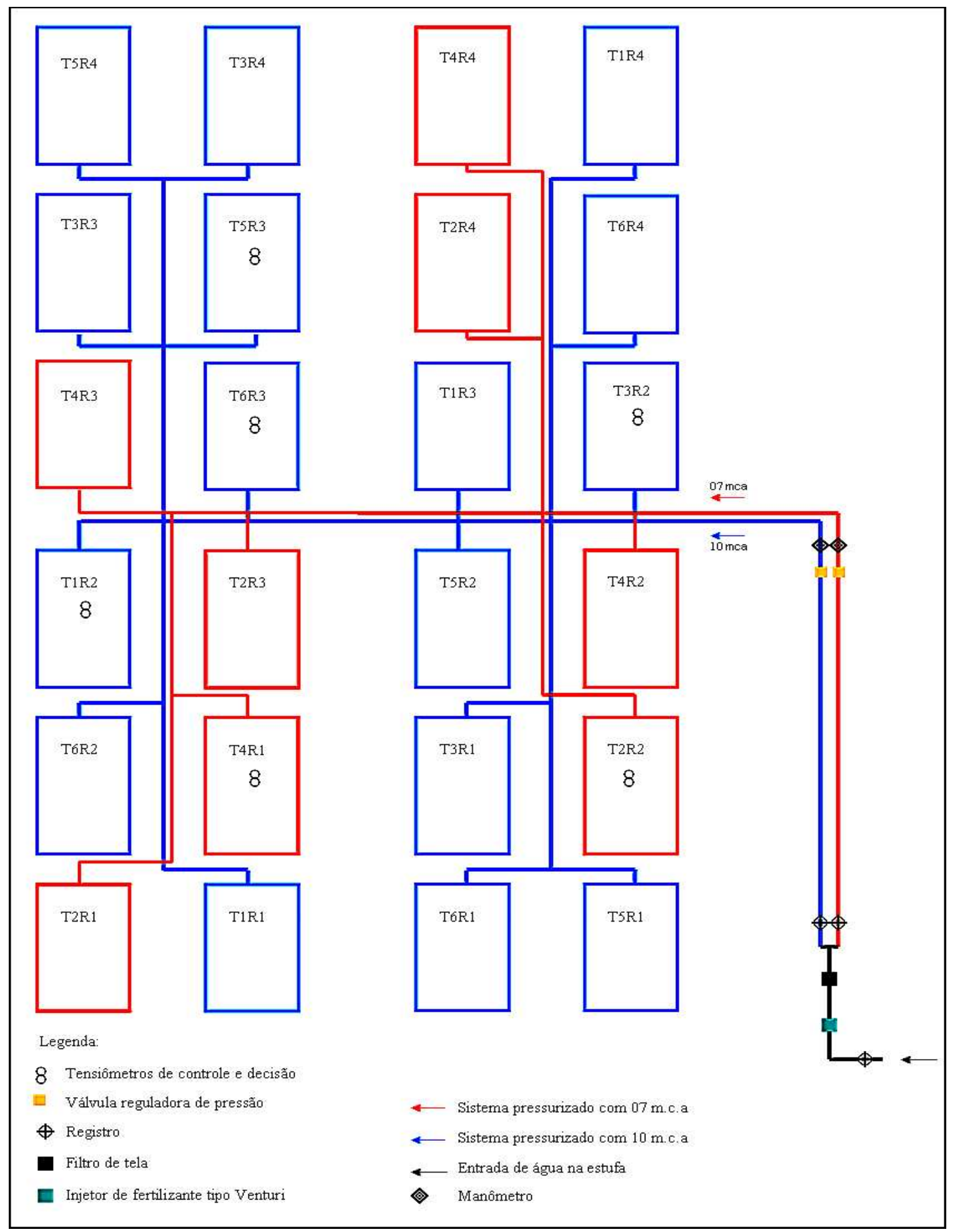

Figura 1. Esquema geral da área experimental (cultivo protegido). 


\subsection{Cálculo do espaçamento entre emissores na linha lateral}

Os cálculos para determinação dos espaçamentos entre emissores utilizados na linha lateral foram elaborados segundo metodologia desenvolvida por Andrade (2009), considerandose a hipótese de que uma mesma linha lateral possua dois segmentos, cada segmento com um espaçamento entre emissores diferente, mas com o mesmo modelo de emissor, de modo que o metro inicial na entrada da linha lateral tenha a mesma vazão que o último metro, ainda que a diferença de pressão entre o início e o final da linha sejam maiores que os $20 \%$, possibilitando a utilização de gotejadores convencionais em linhas laterais mais longas, economicamente vantajoso. Para o cálculo dos espaçamentos utilizados, estabeleceu a pressão de trabalho no início da linha lateral de $100 \mathrm{kPa}$ e uma variação de pressão permissível de $30 \%$, obtendo-se a pressão de $70 \mathrm{kPa}$ no metro final da linha lateral. Para efeito de cálculo também adotou-se dois espaçamentos comercias como sendo espaçamentos da seção final, $20 \mathrm{~cm}$ e $30 \mathrm{~cm}$, por serem os espaçamentos entre gotejadores mais utilizados na irrigação de hortaliças. A partir desses valores e com base na metodologia desenvolvida por Andrade (2009), calcularam-se os respectivos espaçamentos iniciais de 23,57 cm e 35,36 cm, ajustados para $24 \mathrm{~cm}$ e $36 \mathrm{~cm}$ devido ao processo de fabricação da mangueira.

\subsection{Caracterização dos bulbos de irrigação}

Os bulbos de irrigação foram avaliados em três momentos diferentes, a saber: $\mathrm{M}_{0}$ (imediatamente após término das irrigações), $M_{1}$ (1 hora após o término das irrigações) e $\mathrm{M}_{2}$ (2 horas após o término das irrigações). Para caracterização dos bulbos de irrigação, foram retiradas amostras para análise gravimétrica do solo na direção da linha lateral (eixo X) e na direção perpendicular a linha lateral de irrigação (eixo Y), a partir de um gotejador adotado como referência (Figura 2), na terceira semana de desenvolvimento da cultura.

$\mathrm{Na}$ direção de $\mathrm{Y}$, as amostras foram retiradas a partir da linha central de plantio, em seis pontos, para todos os tratamentos, sendo Ponto 1: na linha de plantio; Ponto 2: a $10 \mathrm{~cm}$ da linha de plantio; Ponto 3: a $20 \mathrm{~cm}$ da linha de plantio, coincidente com o emissor de referência; Ponto 4: a $30 \mathrm{~cm}$ da linha de plantio; Ponto 5: a $40 \mathrm{~cm}$ da linha de plantio; Ponto 6: a $50 \mathrm{~cm}$ da linha de plantio. Na direção de $\mathrm{X}$, o número de pontos amostrados e a distância entre eles variaram de acordo com o espaçamento entre os emissores do tratamento, de maneira que sempre se iniciassem no ponto 3 do eixo $\mathrm{Y}$ e que o último ponto amostrado obrigatoriamente coincidisse com o emissor seguinte da linha lateral. Dessa maneira, os pontos amostrados foram: a) espaçamento de $20 \mathrm{~cm}$ (três pontos amostrados): ponto inicial, a $10 \mathrm{~cm}$ e a $20 \mathrm{~cm}$ do ponto inicial; b) espaçamento de $24 \mathrm{~cm}$ (quatro pontos amostrados): ponto inicial, a $8 \mathrm{~cm}$, a $16 \mathrm{~cm}$ e a $24 \mathrm{~cm}$ do ponto inicial; c) espaçamento de $30 \mathrm{~cm}$ (quatro pontos amostrados): ponto inicial, a 10 $\mathrm{cm}$, a $20 \mathrm{~cm}$ e a $30 \mathrm{~cm}$ do ponto inicial; d) espaçamento de $36 \mathrm{~cm}$ (cinco pontos amostrados): ponto inicial, a $9 \mathrm{~cm}$, a $18 \mathrm{~cm}$, a 27 e a $36 \mathrm{~cm}$ do ponto inicial. 


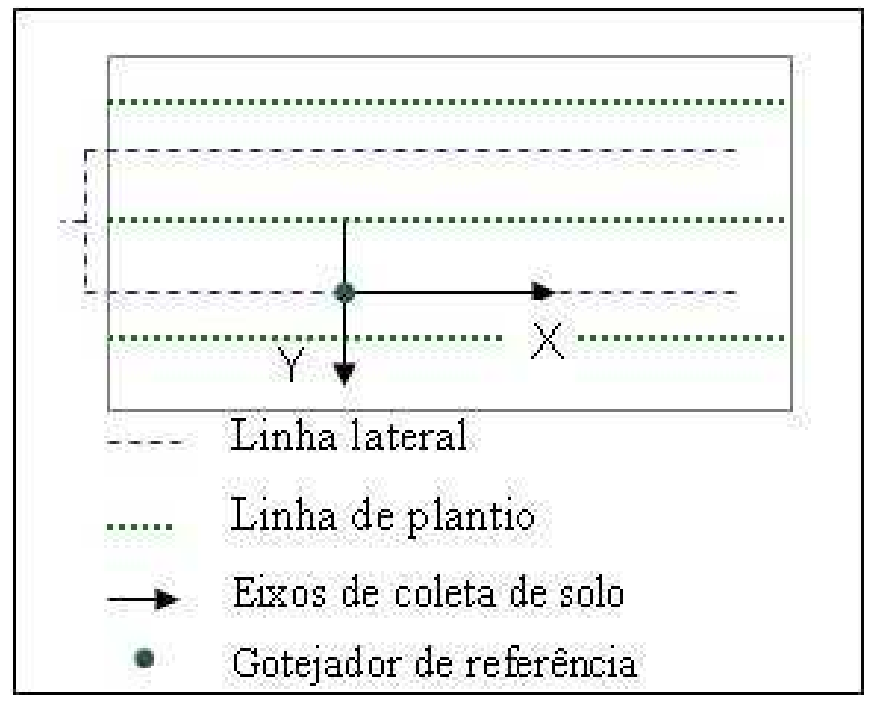

Figura 2. Sentido de coleta de solo para análise gravimétrica

Em cada ponto amostrado foram retiradas amostras de solo em 4 profundidades: $0-5 \mathrm{~cm}$, 5-10 cm, $10-20 \mathrm{~cm}$ e $20-30 \mathrm{~cm}$. As amostras foram coletadas com o auxílio de um trado e imediatamente pesadas para obtenção do peso úmido. Posteriormente, as amostras foram secas em estufa $105^{\circ} \mathrm{C}$ até apresentarem peso constante, para obtenção dos valores de umidade do solo pelo métodos gravimétrico. Os gráficos que caracterizam os bulbos de irrigação foram elaborados com o programa SURFER 8.0, a partir dos valores gravimétricos obtidos em campo. Para cada tratamento avaliado, elaborou-se um gráfico representativo do eixo $\mathrm{X}$ e um representativo do eixo $\mathrm{Y}$, em cada tempo de irrigação considerado $\left(\mathrm{M}_{0}, \mathrm{M}_{1}\right.$ e $\left.\mathrm{M}_{2}\right)$, resultando em 6 gráficos por tratamento, num total de 36 gráficos.

\subsection{Instalação e condução da cultura}

Utilizou-se sementes de rabanete (Raphanus sativus L.) híbrido F1 n ${ }^{\circ} 19$ de ciclo total de até 5 semanas. As semeaduras foram realizadas manualmente, com desbaste após uma semana. Cada parcela foi composta por um canteiro de $1 \mathrm{~m}$ de largura por $5 \mathrm{~m}$ de comprimento, contendo três fileiras de plantas espaçadas de $0,20 \mathrm{~m}$ entre linhas e aproximadamente $0,09 \mathrm{~m}$ na linha. Os tratos culturais e defesa fitossanitária foram devidamente realizados, sempre que necessário. $\mathrm{O}$ solo foi previamente corrigido e adubado segundo recomendações de Van Raij et al. (1997), com base na amostra inicial de solo, coletada para determinação de suas características físicas e químicas na profundidade de $0-20 \mathrm{~cm}$. No momento do plantio, o solo apresentava as características físicas: $1,36 \mathrm{~g} \mathrm{~cm}^{-3}$ de densidade do solo e textura arenosa (900 $\mathrm{g} \mathrm{kg}^{-1}$ de areia, 27 $\mathrm{g} \mathrm{kg}^{-1}$ de silte e $71 \mathrm{~g} \mathrm{~kg}^{-1}$ de argila).

\subsection{Parâmetros avaliados}

Parâmetros físicos: todas as plantas úteis de cada parcela foram pesadas para obtenção dos resultados de matéria fresca total, matéria fresca por metro linear, matéria seca total, e matéria seca por metro linear. As raízes de rabanete foram colhidas, separadas da parte aérea, 
lavadas e pesadas para a determinação da matéria fresca, utilizando-se uma balança digital instalada no próprio local. Após a determinação do peso de matéria fresca, as plantas foram acondicionadas em sacos de papel e colocadas em estufa de circulação forçada de ar a $65^{\circ} \mathrm{C}$ até obterem peso constante, para a determinação do peso de matéria seca. $\mathrm{Na}$ determinação de matéria fresca e seca por metro linear optou-se pela utilização dos pesos médios por planta multiplicados pelo número de plantas pertencente a um metro de plantio, em cada tratamento. Para obtenção do diâmetro médio das raízes de rabanete foram medidos os diâmetros longitudinais e transversais de 3 plantas por parcela, escolhidas aleatoriamente, com o auxílio de um paquímetro digital.

Análise dos bulbos de irrigação: a avaliação dos bulbos de irrigação pode evidenciar a tendência de caminhamento da água no solo e de que maneira ocorre a sobreposição de bulbos na desejável formação de um faixa úmida. A análise ocorreu com auxílio dos gráficos elaborados, conforme item 4.4 .

\subsection{Delineamento estatístico}

A análise estatística foi realizada de duas maneiras, com delineamento experimental inteiramente casualizado e parcelas de $1,0 \mathrm{~m}$ de largura e 5,0 m de comprimento. Na primeira avaliação (Avaliação I) comparou-se todos os segmentos iniciais e finais das linhas laterais propostas, com o objetivo de verificar se determinado segmento avaliado obteve resultados significativamente diferentes em relação a outro segmento, pertencente ou não à mesma linha lateral. Nesse caso foram considerados 6 tratamentos e 4 repetições, cada tratamento representativo de um segmento da linha lateral e formado a partir da combinação de quatro espaçamentos entre os emissores $(20,24,30$ e $36 \mathrm{~cm})$ e duas pressões de serviço $(70$ e $100 \mathrm{kPa})$, em que: $\mathrm{T} 1=24 \mathrm{~cm}$ e $100 \mathrm{kPa}$ (segmento inicial da situação 1); T2 $=20 \mathrm{~cm}$ e $70 \mathrm{kPa}$ (segmento final das situações 1 e 3); T3 = $36 \mathrm{~cm}$ e $100 \mathrm{kPa}$ (segmento inicial da situação 2); T4 = $30 \mathrm{~cm}$ e $70 \mathrm{kPa}$ (segmento final das situações 2 e 4); T5 $=20 \mathrm{~cm}$ e $100 \mathrm{kPa}$ (segmento inicial da situação 3); $\mathrm{T} 6=30 \mathrm{~cm}$ e $100 \mathrm{kPa}$ (segmento inicial da situação 4). A segunda avaliação (Avaliação II) comparou as linhas laterais propostas entre si. Nesse caso foram considerados 4 tratamentos (situações), cada um composto pela média dos resultados do segmento inicial e final de cada linha lateral, em que:

- Situação 1: segmento inicial (24 cm e $100 \mathrm{kPa})+$ segmento final $(20 \mathrm{~cm}$ e $70 \mathrm{kPa})$.

- Situação 2: segmento inicial $(36 \mathrm{~cm}$ e $100 \mathrm{kPa})+$ segmento final $(30 \mathrm{~cm}$ e $70 \mathrm{kPa})$.

- Situação 3: segmento inicial $(20 \mathrm{~cm}$ e $100 \mathrm{kPa})+$ segmento final $(20 \mathrm{~cm}$ e $70 \mathrm{kPa})$

- Situação 4: segmento inicial $(30 \mathrm{~cm}$ e $100 \mathrm{kPa})$ + segmento final $(30 \mathrm{~cm}$ e $70 \mathrm{kPa})$

\section{RESULTADOS E DISCUSSÃO}

\subsection{Bulbos de irrigação}

As Figuras 3 a 5 representam os valores de umidade do solo com base em volume, nos momentos $\mathrm{M}_{0}, \mathrm{M}_{1}$ e $\mathrm{M}_{2}$, para a direção $\mathrm{X}$ de cada tratamento proposto. Nesta direção de coleta, observou-se de que maneira a água aplicada se distribuiu no solo, na região compreendida entre 
dois emissores consecutivos da linha lateral. Nos tratamentos 1, 2, 4, 5 e 6 houve boa distribuição da água aplicada ao solo, sendo que a maior parte da região compreendida entre os emissores apresentou valores de umidade do solo, no mínimo, dentro da faixa de água disponível à cultura (valores acima do ponto de murcha permanente, 12,14\%). Nestes tratamentos os menores valores de umidade do solo foram verificados nas camadas mais profundas. Em alguns casos, como nos tratamentos 1,2 e 5, verificou-se valores próximos ao ponto de murcha permanente; no entanto, estes baixos valores de umidade foram constatados em camadas abaixo da profundidade efetiva da cultura (Z: $20 \mathrm{~cm})$, região de maior absorção de água e nutrientes pela planta. No tratamento 3 foram observadas regiões de solo com umidade muito baixa, inferior ao ponto de murcha permanente. Nesse caso, diferentemente dos demais tratamentos, as regiões mais secas não se concentraram apenas abaixo da profundidade efetiva da cultura; após uma hora $\left(\mathrm{M}_{1}\right)$ e duas horas $\left(\mathrm{M}_{2}\right)$ da irrigação, observou-se regiões de baixa umidade distribuídas em quase todas as profundidades avaliadas, desde a superfície, principalmente na região central entre os emissores. Esse tratamento representou a seção inicial de uma linha lateral com emissores espaçados a 36 $\mathrm{cm}$. Este foi o maior espaçamento entre emissores utilizado e evidencia que, nesse caso, a água não se distribuiu de maneira adequada ao solo, ainda que a lâmina de irrigação aplicada tenha sido a mesma. Portanto, ainda que as vazões sejam iguais entre a seção inicial e final da linha lateral, deve-se considerar que o espaçamento máximo entre emissores é limitado pelas características físicas do solo, para que ocorra sobreposição dos bulbos.

A forma e diâmetro dos bulbos úmidos dependem do equilíbrio de forças gravitacionais e capilares e está relacionada, entre outros fatores, à quantidade de água aplicada e à textura do solo. Em solos arenosos os bulbos úmidos tendem a ter um diâmetro menor do que em solos argilosos, diminuindo a distância máxima entre emissores para que ocorra sobreposição de bulbos. Segundo Bernardo et al. (2006), em solos argilosos o potencial gravitacional torna-se importante apenas depois de certo tempo, sendo que inicialmente a água avança em todas as direções com a mesma velocidade. Em solos arenosos, o potencial gravitacional atua logo após início da irrigação e o movimento vertical, de cima para baixo, passa a ser o principal componente do potencial total de água no solo. Exemplo disso são os trabalhos desenvolvidos para determinação do diâmetro de bulbo molhado e do espaçamento máximo entre emissores. Hung (1995) calculou o espaçamento máximo entre emissores, em função do tipo de solo para emissores de $2 \mathrm{~L} \cdot \mathrm{h}^{-1}$ e relatou espaçamentos máximos de $0,3,0,6$ e 1,0 m, respectivamente, para solos arenosos, médios e argilosos. Karmeli \& Keller (1975) avaliaram diâmetro de bulbo molhado para emissores de $4 \mathrm{~L}^{-1}{ }^{-1}$ em solos homogêneos e citam valores $0,5,0,9$ e $1,1 \mathrm{~m}$ de diâmetro para solos arenosos, médios e argilosos, respectivamente. Em ambos os trabalhos, os diâmetros de bulbo molhado foram menores em solos arenosos que em solos argilosos, evidenciando a importância da textura do solo na formação dos bulbos.

As Figuras 6 a 8 representam os valores de umidade do solo com base em volume, nos momentos $\mathrm{M}_{0}, \mathrm{M}_{1}$ e $\mathrm{M}_{2}$, para a direção $\mathrm{Y}$ de cada tratamento proposto, ou seja, perpendicular à linha lateral. Os gráficos seguem tendências semelhantes em todos os tratamentos e observa-se claramente a formação dos bulbos de irrigação, a partir de um único emissor. Para todos os tratamentos, à exceção do Tratamento 2 , verificou-se maior tendência de infiltração de água no sentido vertical (em profundidade) que no sentido horizontal, provavelmente devido à textura arenosa do solo. No Tratamento 2, principalmente duas horas após a irrigação $\left(\mathrm{M}_{2}\right)$, observa-se que a água não avançou para as camadas mais profundas do solo, sendo que valores de umidade muito baixos foram verificados em profundidades de menos de $15 \mathrm{~cm}, \operatorname{logo}$ abaixo do emissor. 
Acredita-se que essa tendência, incomum às demais, tenha sido causada por uma camada de solo compactado ou algum obstáculo natural, pois observa-se claramente que a água avança em profundidade em apenas um dos lados do emissor.

De maneira geral, avaliando-se os bulbos de irrigação nas direções $\mathrm{X} \mathrm{e} \mathrm{Y}$, quase todos os tratamentos apresentaram tendências semelhantes de distribuição de água no solo; apenas o tratamento 3 apresentou áreas de déficit hídrico na profundidade efetiva de raízes, justamente no maior espaçamento entre emissores avaliado. 


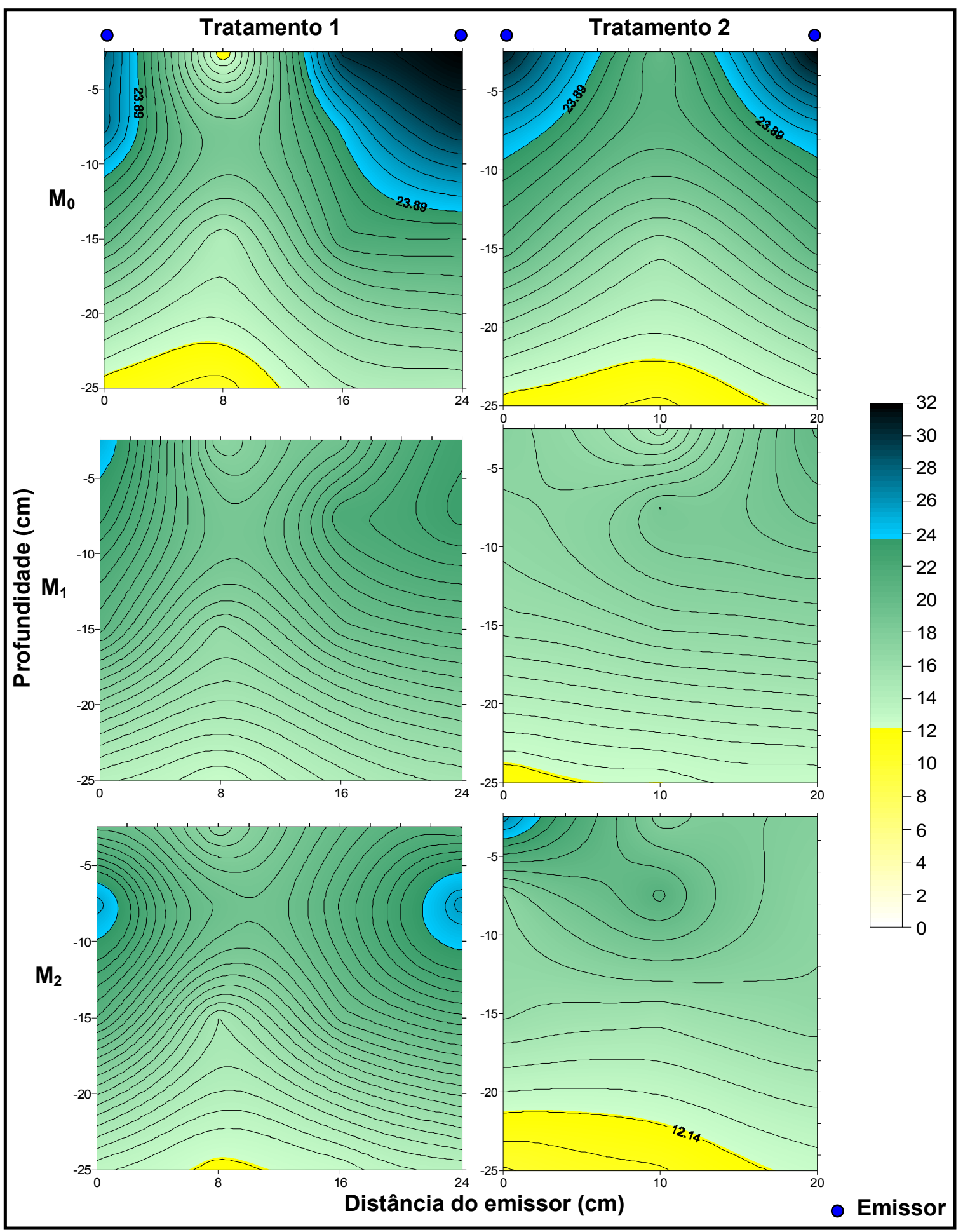

Figura 3. Representação gráfica da umidade do solo na direção $X$ dos tratamentos 1 e 2 com base em \% de volume, imediatamente após irrigação $\left(\mathrm{M}_{0}\right)$, uma hora $\left(\mathrm{M}_{1}\right)$ e duas horas $\left(\mathrm{M}_{2}\right)$ depois. 


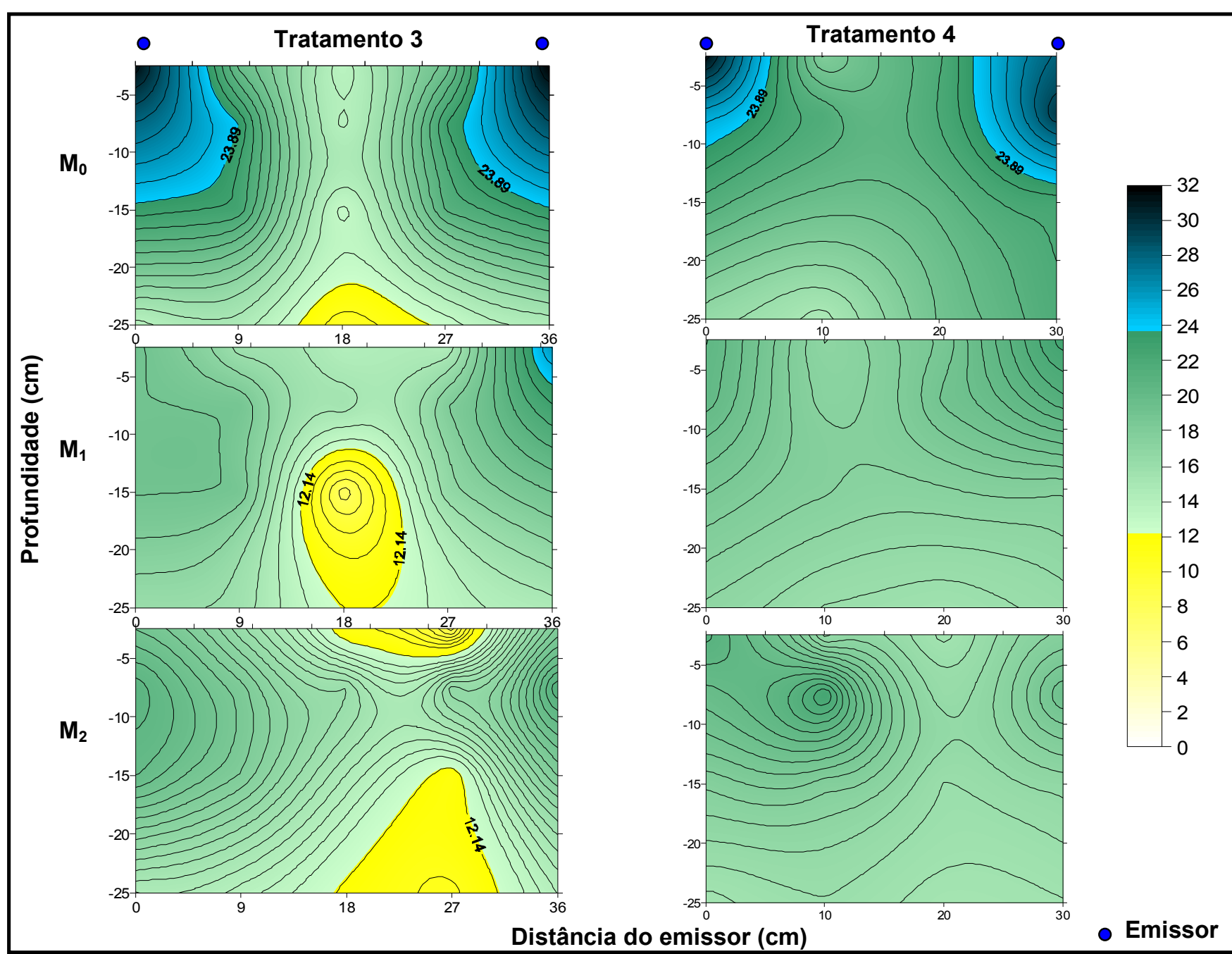

Figura 4. Representação gráfica da umidade do solo na direção $X$ dos tratamentos 3 e 4 com base em \% de volume, imediatamente após irrigação $\left(\mathrm{M}_{0}\right)$, uma hora $\left(\mathrm{M}_{1}\right)$ e duas horas $\left(\mathrm{M}_{2}\right)$ depois. 


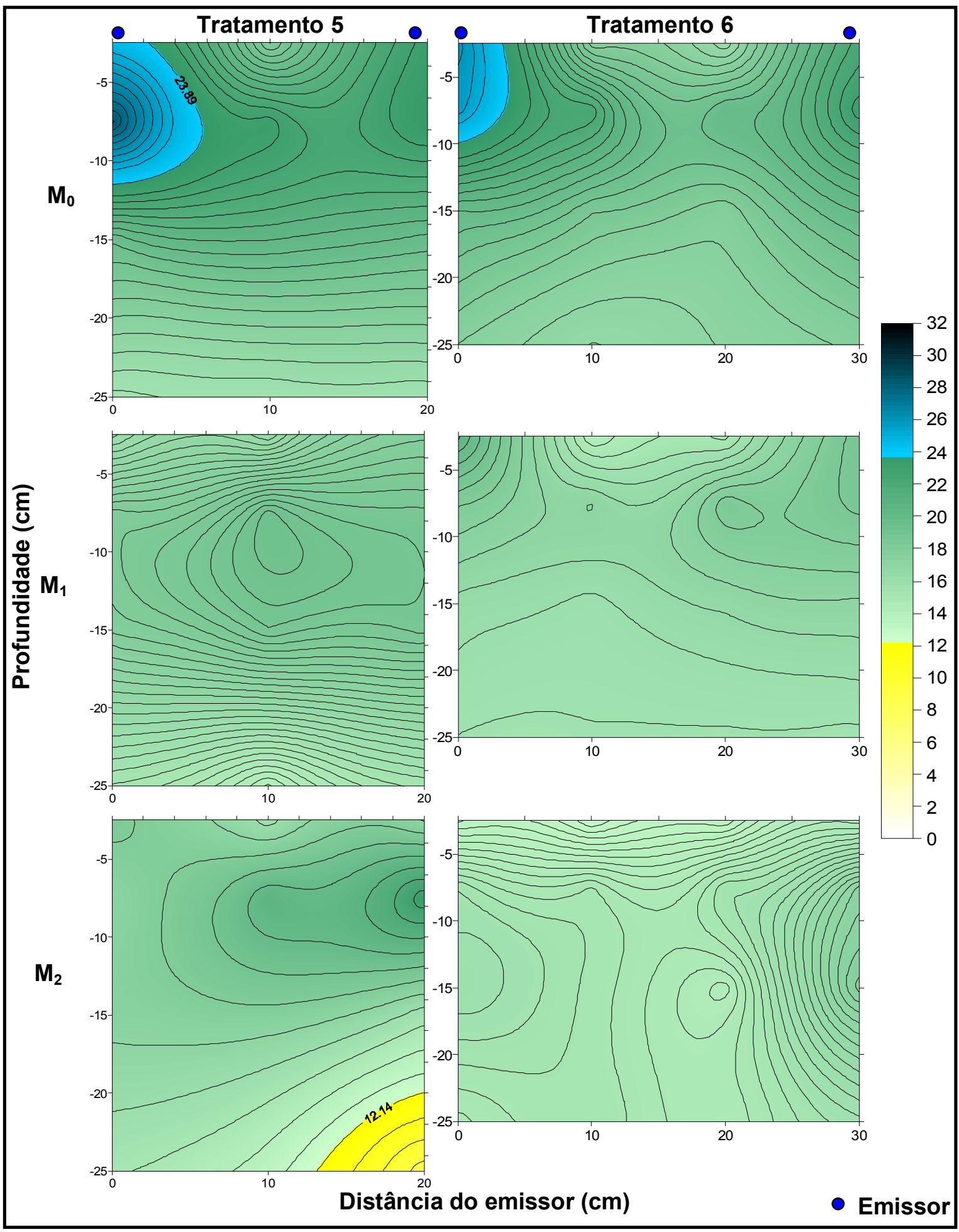

Figura 5. Representação gráfica da umidade do solo na direção $X$ dos tratamentos 5 e 6 com base em \% de volume, imediatamente após irrigação $\left(\mathrm{M}_{0}\right)$, uma hora $\left(\mathrm{M}_{1}\right)$ e duas horas $\left(\mathrm{M}_{2}\right)$ depois. 


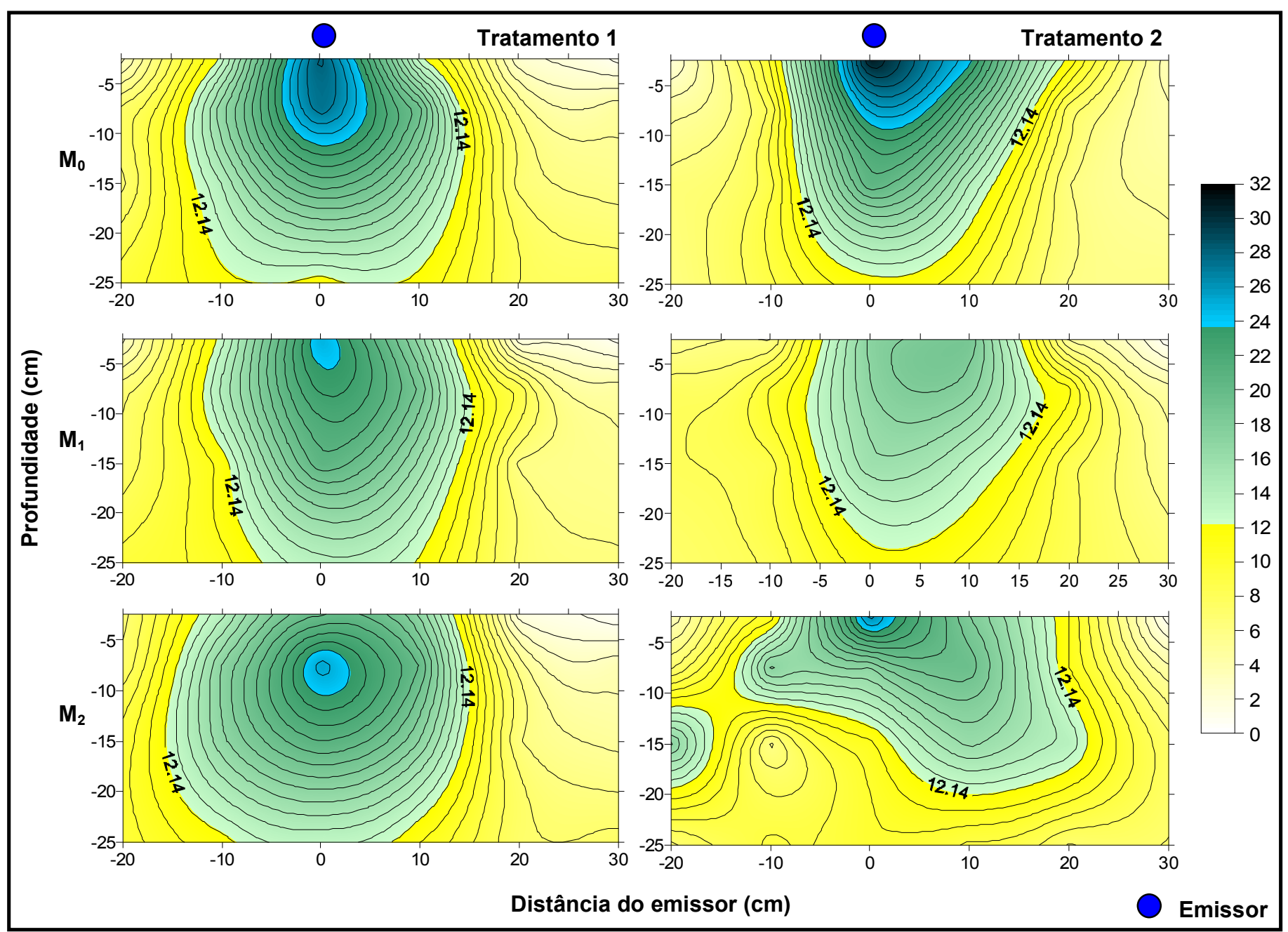

Figura 6. Representação gráfica da umidade do solo na direção $\mathrm{Y}$ dos tratamentos 1 e 2, com base em \% de volume, imediatamente após irrigação $\left(\mathrm{M}_{0}\right)$, uma hora $\left(\mathrm{M}_{1}\right)$ e duas horas $\left(\mathrm{M}_{2}\right)$ depois. 


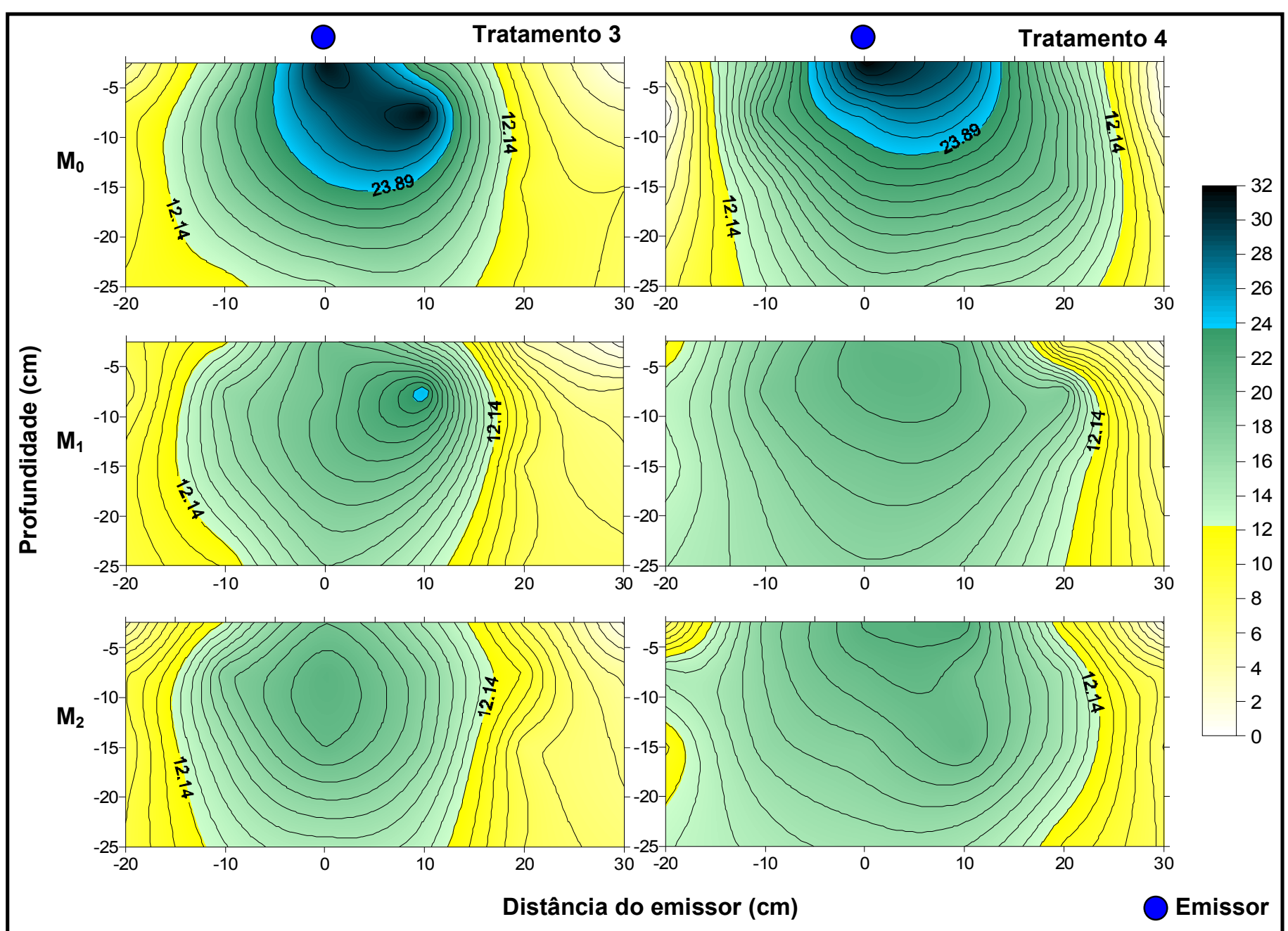

Figura 7. Representação gráfica da umidade do solo na direção Y dos tratamentos 3 e 4, com base em \% de volume, imediatamente após irrigação $\left(\mathrm{M}_{0}\right)$, uma hora $\left(\mathrm{M}_{1}\right)$ e duas horas $\left(\mathrm{M}_{2}\right)$ depois. 


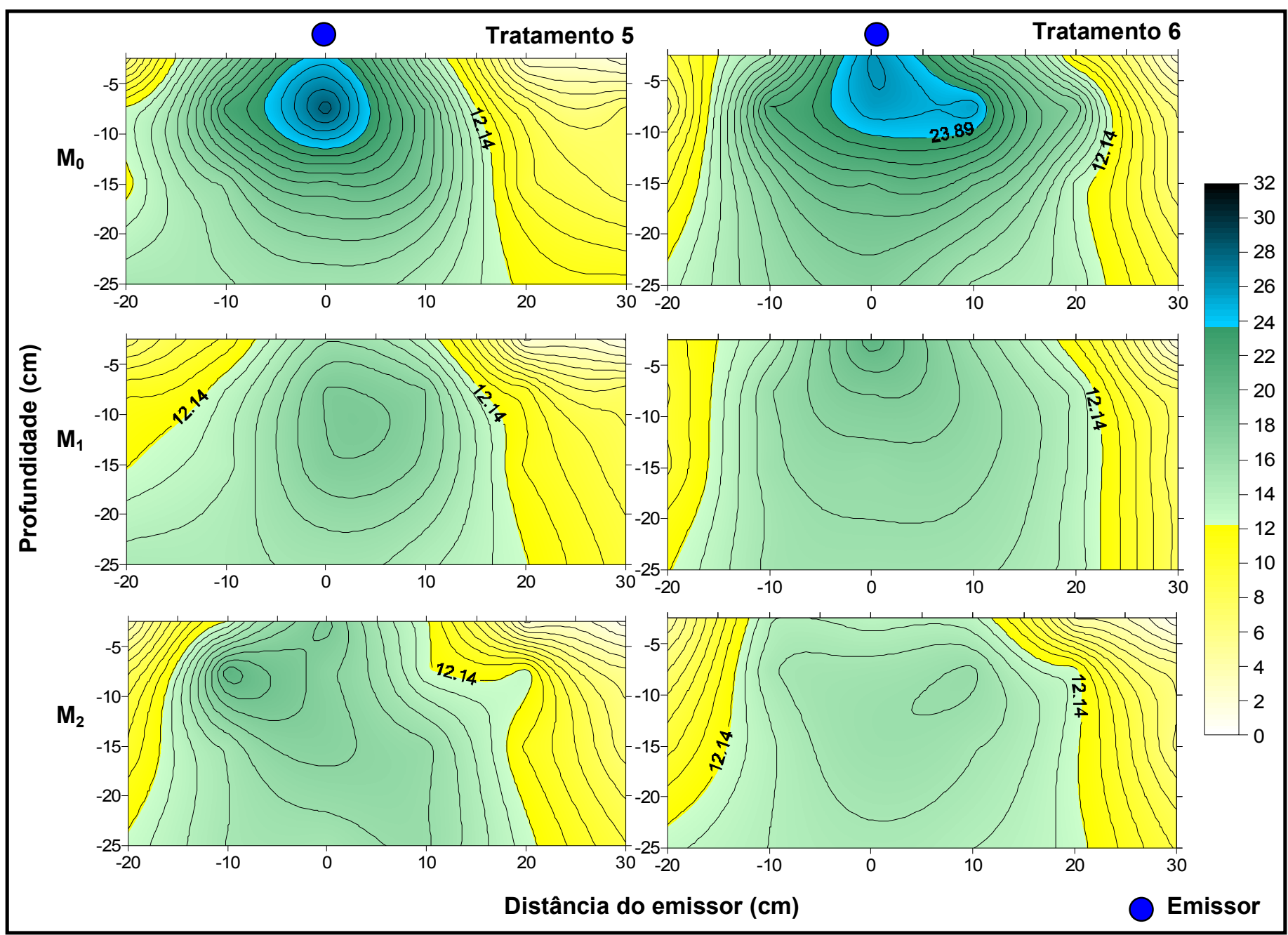

Figura 8. Representação gráfica da umidade do solo na direção $\mathrm{Y}$ dos tratamentos 5 e 6 com base em \% de volume, imediatamente após irrigação $\left(\mathrm{M}_{0}\right)$, uma hora $\left(\mathrm{M}_{1}\right)$ e duas horas $\left(\mathrm{M}_{2}\right)$ depois. 


\subsection{Parâmetros físicos}

\subsubsection{Avaliação I: comparação entre inícios e finais de linha lateral}

Os valores de parâmetros físicos obtidos podem ser verificados na Tabela 1 .

Tabela 1. Valores de peso de matéria fresca total, matéria fresca por metro linear, matéria seca total, matéria seca por metro linear e diâmetro de rabanete, entre tratamentos

\begin{tabular}{cccccc}
\hline Tratamento & $\begin{array}{c}\text { Matéria } \\
\text { fresca total }\end{array}$ & $\begin{array}{c}\text { Matéria fresca } \\
\text { por metro } \\
\text { linear }\end{array}$ & $\begin{array}{c}\text { Matéria seca } \\
\text { total }\end{array}$ & $\begin{array}{c}\text { Matéria seca } \\
\text { por metro } \\
\text { linear }\end{array}$ & Diâmetro \\
\cline { 2 - 6 } & \multicolumn{1}{c}{$(\mathrm{g})$} & $\left(\mathrm{g} \mathrm{m}^{-1}\right)$ & $(\mathrm{g})$ & $\left(\mathrm{g} \mathrm{m}^{-1}\right)$ & $(\mathrm{mm})$ \\
\hline 1 & $845.00 \mathrm{a}$ & $221.19 \mathrm{a}$ & $37.4675 \mathrm{a}$ & $9.8800 \mathrm{a}$ & $34,33 \mathrm{a}$ \\
2 & $1106.00 \mathrm{a}$ & $245.96 \mathrm{a}$ & $44.3150 \mathrm{a}$ & $9.8500 \mathrm{a}$ & $35,95 \mathrm{a}$ \\
3 & $944.00 \mathrm{a}$ & $206.18 \mathrm{a}$ & $44.1625 \mathrm{a}$ & $9.7325 \mathrm{a}$ & $34,60 \mathrm{a}$ \\
4 & $946.00 \mathrm{a}$ & $231.53 \mathrm{a}$ & $38.7475 \mathrm{a}$ & $9.6050 \mathrm{a}$ & $35,48 \mathrm{a}$ \\
5 & $936.75 \mathrm{a}$ & $235.61 \mathrm{a}$ & $38.9375 \mathrm{a}$ & $9.8925 \mathrm{a}$ & $35,45 \mathrm{a}$ \\
6 & $1055.50 \mathrm{a}$ & $265.22 \mathrm{a}$ & $39.4750 \mathrm{a}$ & $9.8475 \mathrm{a}$ & $36,34 \mathrm{a}$ \\
\hline $\mathrm{CV}(\%)$ & 22.04 & 13.97 & 18.90 & 13.03 & 4,53 \\
\hline \hline
\end{tabular}

Médias seguidas de letras iguais na vertical não diferem estatisticamente pelo Teste Tukey a 5\%.

Os resultados mostraram que não houve diferença significativa entre os tratamentos pelo teste de Tukey a 5\% para os parâmetros físicos avaliados. Assim, os resultados foram estatisticamente iguais entre todas as seções iniciais e finais avaliadas, independentemente do espaçamento entre emissores e da pressão utilizada.

Como citado anteriormente, todos os tratamentos apresentaram tendências semelhantes de distribuição de água no solo, à exceção do Tratamento 3 , onde verificou-se que a água não se distribuiu de maneira adequada no solo. A distribuição irregular da água verificada neste tratamento, no entanto, não foi suficiente para causar diferenças significativas nos parâmetros físicos avaliados.

O peso fresco médio por planta obtido foi de 20,16 g, valor superior àqueles relatados por Pereira et al. (1999), que citam valores médios de peso fresco de $16,07 \mathrm{~g}$ e 12,27 $\mathrm{g}$, respectivamente para níveis de reposição de água equivalentes a $100 \%$ e $60 \%$ da capacidade de campo. No entanto, são inferiores aos obtidos por Torres et al. (2003), que citam valores médios variando de $22,04 \mathrm{~g}$ a 28,63 $\mathrm{g}$ em estudo sobre o efeito da densidade de plantio na cultura. Os mesmos autores relatam ainda valores de diâmetro médio de $31,49 \mathrm{~mm}$ a $33,57 \mathrm{~mm}$, inferiores aos obtidos neste experimento. Em campo é possível a obtenção de rabanetes com diâmetro e peso médio superior aos apresentados, estendendo-se em alguns dias o ciclo da cultura. No entanto, essa prática não é recomendada por aumentar o risco de rachaduras e isoporização nas raízes, diminuindo seu valor comercial.

\subsubsection{Avaliação II: comparação entre linhas laterais (Situações)}

Os valores obtidos de parâmetros físicos podem ser observados na Tabela 2. 
Tabela 2. Valores de peso de matéria fresca total, matéria fresca por metro linear, matéria seca total, matéria seca por metro linear e diâmetro de rabanete, entre situações

\begin{tabular}{cccccc}
\hline $\begin{array}{c}\text { Tratamento } \\
\text { (Situação) }\end{array}$ & $\begin{array}{c}\text { Matéria } \\
\text { fresca total }\end{array}$ & $\begin{array}{c}\text { Matéria fresca } \\
\text { por metro linear }\end{array}$ & $\begin{array}{c}\text { Matéria } \\
\text { seca total }\end{array}$ & $\begin{array}{c}\text { Matéria seca por } \\
\text { metro linear }\end{array}$ & Diâmetro \\
\hline 1 & \multicolumn{1}{c}{$(\mathrm{g})$} & $\left(\mathrm{g} \mathrm{m}^{-1}\right)$ & $(\mathrm{g})$ & $\left(\mathrm{g} \mathrm{m}^{-1}\right)$ & $(\mathrm{mm})$ \\
2 & $975,50 \mathrm{a}$ & $233,57 \mathrm{a}$ & $40,8912 \mathrm{a}$ & $9,8650 \mathrm{a}$ & $35,14 \mathrm{a}$ \\
3 & $945,00 \mathrm{a}$ & $218,86 \mathrm{a}$ & $41,4550 \mathrm{a}$ & $9,6688 \mathrm{a}$ & $35,04 \mathrm{a}$ \\
4 & $1021,38 \mathrm{a}$ & $240,78 \mathrm{a}$ & $41,6263 \mathrm{a}$ & $9,8713 \mathrm{a}$ & $35,70 \mathrm{a}$ \\
$\mathrm{CV}(\%)$ & $1000,75 \mathrm{a}$ & $248,38 \mathrm{a}$ & $39,1113 \mathrm{a}$ & $9,7263 \mathrm{a}$ & $35,91 \mathrm{a}$ \\
\hline \hline
\end{tabular}

Médias seguidas de letras iguais na vertical não diferem estatisticamente pelo Teste Tukey a 5\%.

Os resultados mostram que não houve diferença significativa entre as situações para os parâmetros físicos avaliados, evidenciando que as linhas laterais de espaçamentos variados (Situações 1 e 3) apresentaram desempenho equivalente às linhas laterais de espaçamento único (Situações 2 e 4).

\section{CONCLUSÕES}

Nas condições em que o presente trabalho foi realizado, pode-se concluir que:

- Não houve diferença significativa entre os segmentos iniciais e finais das linhas laterais, para todos os parâmetros avaliados.

- Não houve diferença significativa entre as linhas laterais de espaçamento variado e linhas laterais de espaçamento único, para todos os parâmetros avaliados.

- $\quad$ O uso de diferentes espaçamentos entre gotejadores na mesma linha lateral, que permite aumentar o comprimento da linha e diminuir seu custo de fabricação por metro de mangueira, não apresentou diferença significativa para a maioria dos parâmetros e pode ser considerada uma técnica viável para a irrigação por gotejamento.

\section{REFERÊNCIAS BIBLIOGRÁFICAS}

ANDRADE, L. A. de. Estudo da uniformidade de emissão de água utilizando diferentes espaçamentos entre gotejadores na linha lateral. 2009. 87 p. Tese (Doutorado em Agronomia) - Faculdade de Ciências Agronômicas, UNESP, Botucatu, 2009.

AZEVEDO, L. P. de. Uso de dois espaçamentos entre gotejadores na mesma linha lateral e seus efeitos sobre a formação do bulbo molhado, produtividade e qualidade de rabanete (Raphanus sativus L.). Tese (Doutorado em Agronomia) - Faculdade de Ciências Agronômicas, Universidade Estadual Paulista, Botucatu, 2008.

BENAMI, A.; OFEN, A. Irrigation engineering: sprinkler, trickle, surface irrigation, principles, design and agricultural practices. Haifa: IESP, 1984. 
BERNARDO, S.; SOARES, A. V.; MANTOVANI, E. C. Manual de irrigação. Viçosa: UFV, 2006. 625p.

FILGUEIRA, F.A.R. Novo manual de olericultura: agrotecnologia moderna na produção e comercialização de hortaliças. Viçosa: UFV, 2000. 402p.

FRIZZONE, J. A.; VIEIRA, A. T.; PAZ, V. P. S.; BOTREL, T. A. Caracterização hidráulica de um tubo gotejador. Revista Brasileira de Engenharia Agrícola e Ambiental, Campina Grande, v. 2, n. 3, p. 278-283, 1998.

HUNG, J. Y. T. Determination of emitter spacing and irrigation run time incliding plant root depth. In: International Microirrigation Congress, 5., 1995, Orlando. Proceedings .. St Joseph: ASAE, 1995. p 292-298.

KARMELI, D.; KELLER, J. Trickle irritation design. Glendora: Rain Bird Sprinkler Manufacturing Corporation, 1975. 133 p.

KELLER, J.; BLIESNER, R. D. Sprinkle and trickle irrigation. New York: Avi Book, 1990. $652 \mathrm{p}$.

MANTOVANI, E. C.; BERNARDO, S; PALARETTI, L. F. Irrigação: princípios e métodos. Viçosa: UFV, 2007. 358p.

PEREIRA, A. J.; et al. Efeito dos níveis de reposição e freqüência de irrigação sobre a produção e qualidade do rabanete. Revista Brasileira de Engenharia Agrícola e Ambiental, Campina Grande, v. 3, n. 1, p. 117-120, 1999.

RICHARDS, L. A. Physical conditions of water in soil. In: BLACK, C. A.; EVANS, D. D.; WHITE, J. L.; ENSMINGE, L. E.; CLARK, F. E. (Ed.). Methods of soil analysis - Physical and mineralogical properties, including statistics of measurements and sampling. Madison, ASASSSA, 1965. p. 128-152.

SANDERS, D. C. Vegetable crop irrigation. Horticulture information leaflet 33-E, North Carolina Cooperative Extension Service. North Carolina State University, 1997.

SANTOS, R. A.; et al. Uniformidade de distribuição de água em irrigação por gotejamento em sub-superfície instalado na cultura de pupunheiras (Bactris gasipaes H.B.K.). In: CONGRESSO BRASILEIRO DE ENGENHARIA AGRÍCOLA, 32., 2003, Goiânia. Anais... Goiânia: SBEA, 2003. CD-ROM.

TORRES, C. A. S.; et al. Avaliação da densidade de plantio sobre a produção e diâmetro de rabanete. Horticultura Brasileira, Brasília, v. 21, n. 2, 2003. Suplemento CD-ROM. Van RAIJ, B. et al. Recomendações de adubação e calagem para o Estado de São Paulo. Campinas: Instituto Agronômico, 1997. 285 p. 